\title{
Antithrombin Activation by Nonsulfated, Non-Polysaccharide Organic Polymer
}

\author{
Bernhard H. Monien and Umesh R. Desai* \\ Department of Medicinal Chemistry and Institute for Structural Biology and Drug Discovery, \\ Virginia Commonwealth University, Richmond, Virginia 23298-0540
}

Received August 27, 2004

Accelerated antithrombin inhibition of procoagulant enzymes has been exclusively achieved with polysulfated polysaccharides. We reasoned that antithrombin activation should be possible with nonsulfated activators based only on carboxylic acid groups. As a proof of the principle, linear poly(acrylic acid)s were found to bind to antithrombin and accelerate inhibition of factor $\mathrm{Xa}$ and thrombin. Our work demonstrates that molecules completely devoid of sulfate groups can activate antithrombin effectively and, more importantly, suggests that it may be possible to develop orally bioavailable, carboxylate-based antithrombin activators.

\section{Introduction}

Antithrombin, a plasma glycoprotein and member of the serpin family of proteins, is an inhibitor of factor $\mathrm{Xa}$ and thrombin, enzymes of the blood coagulation cascade. ${ }^{1,2}$ Although antithrombin is an inhibitor, its reaction with both the enzymes is very slow under physiological conditions. The inhibitor requires an activator to effectively nullify the pro-coagulant enzymes.

Numerous molecules have been found to activate antithrombin. Heparin, a clinically used antithrombinbased anticoagulant for the past 7 decades, ${ }^{3,4}$ has served as a prototypic activator on which all subsequent molecular designs have been based. These designs include the chemically modified heparins and lowmolecular weight heparins. ${ }^{5}$ In addition, a specific fiveresidue sulfated saccharide sequence DEFGH and its derivatives have been studied as potent antithrombin activators. ${ }^{5-9}$ Recently, major advances on chemoenzymatic front have been made to synthesize these small sulfated saccharides. ${ }^{10-14}$ Likewise, some non-heparin molecules have also been investigated as antithrombotics. ${ }^{15-17}$ These possess sulfated or phosphorylated thrombin binding domain that are non-heparin structures, but retain the highly sulfated DEFGH structure as the critical antithrombin binding domain.

The principal reason proposed for retaining a sulfated polysaccharide structure in the design of antithrombin activators is the nature of antithrombin-heparin interaction. A specific sequence of five saccharide residues in the heparin chain is found essential for tight binding, ${ }^{18-20}$ which allows heparin to exert its effect on antithrombin at low concentrations. Yet, low-affinity heparin, with a low antithrombin binding affinity of $\sim 25-30 \mathrm{~kJ} / \mathrm{mol}$, activates the inhibitor some 60 -fold. This activation arises from the bridging of the inhibitor and the enzyme on the sulfated polysaccharide. ${ }^{21}$

Sulfated polysaccharides are known to bind many proteins, ${ }^{22-24}$ thus explaining their severe side-effects..$^{25,26}$ In contrast, fondaparinux, a pentasaccharide DEFGH derivative, appears to have reduced side-effects,

* To whom correspondence should be addressed. Tel: (804) 8287328. Fax: (804) 828-7625. E-mail: urdesai@vcu.edu.

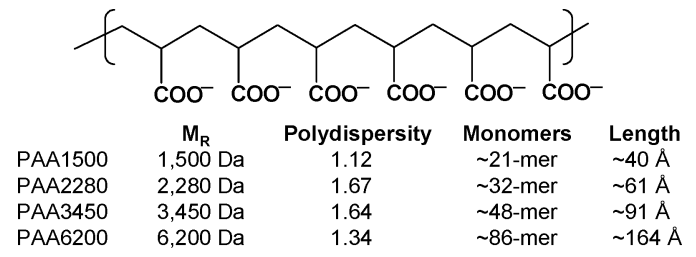

Figure 1. Structure of poly(acrylic acid)s (PAA) studied for antithrombin activation. $M_{\mathrm{R}}=$ average molecular weight; Length refers to the predicted length of an extended linear chain.

yet the risk for enhanced bleeding is not eliminated. ${ }^{27-30}$ Thus, new heparin-like mimics are desirable.

Engineering new antithrombin activators without side-effects, and possibly with oral activity, would represent a major advance in anticoagulation therapy. The fundamental assumptions made to-date in designing antithrombin activators are that the designs (i) have to be polysaccharide-based and (ii) should possess multiple sulfate $\left(\mathrm{OSO}_{3}{ }^{-}\right)$groups. Previously we demonstrated that antithrombin activation is possible without a saccharide scaffold. ${ }^{31-33}$ As a further challenge, we reasoned that this activation should also be possible with nonsulfated molecules based only on carboxylic acid groups.

The work described here demonstrates the proof of this principle wherein poly(acrylic acid)s are found to bind and activate antithrombin. This suggests that one may be able to develop appropriate organic scaffold(s) containing only carboxylic acid groups, without any sulfate groups, as antithrombin activator(s). An advantage with carboxylate-based activators is that they may be potentially converted into prodrugs that possess oral bioavailability, a concept deemed impossible with heparin.

\section{Results}

Equilibrium Binding to Antithrombin. To test whether linear poly(acrylic acid)s (PAAs) interact with plasma antithrombin, we followed the change in fluorescence of an external probe, TNS, as function of PAA concentration at $\mathrm{pH} 6.0$ and $\mathrm{pH} 7.4$ for four polymers of differing chain length (Figure 1). We and others have previously exploited this technique to study the interac- 


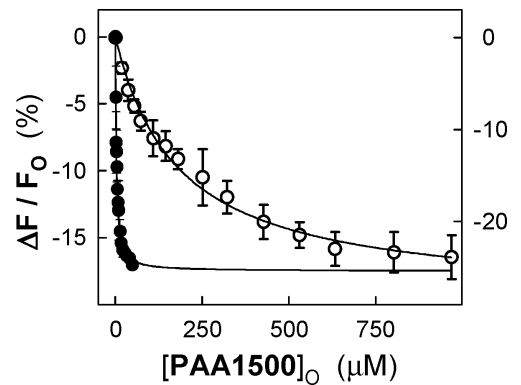

Figure 2. Representative fluorescence titration of antithrombin-TNS complex as a function of PAA1500 at $\mathrm{pH} 6.0(\bullet)$ and $\mathrm{pH} 7.4(\bigcirc)$. The $K_{\mathrm{D}}$ values for the interactions were determined by nonlinear least-squares fittings of two or three averaged measurements to the quadratic binding equation (solid lines). ${ }^{35,36}$ See Experimental Section for details.

Table 1. Equilibrium Dissociation Constants $\left(K_{\mathrm{D}}\right)$ of PAA-Antithrombin Complexes at $\mathrm{pH} 6.0$ and $7.4^{a}$

\begin{tabular}{lll} 
& $\mathrm{pH} 6.0$, & $\mathrm{pH} \mathrm{7.4,}$ \\
$I 0.05$, & $I 0.075$, \\
& $25^{\circ} \mathrm{C}, \mu \mathrm{M}$ & $25^{\circ} \mathrm{C}, \mu \mathrm{M}$ \\
\hline PAA1500 & $2.3 \pm 0.2$ & $180 \pm 15$ \\
PAA2280 & $2.3 \pm 0.2$ & $96 \pm 14$ \\
PAA3450 & $1.3 \pm 0.2$ & $91 \pm 15$ \\
PAA6200 & $1.0 \pm 0.1$ & $34 \pm 2^{b}$ \\
DEF $^{c, d}$ & $2.0 \pm 0.6$ & $66 \pm 4$ \\
DEFGH $^{c, d}$ & $\sim 5 \times 10^{-5}$ & $\sim 1.4 \times 10^{-3}$ \\
$(+)-\mathrm{CS}^{c, e}$ & 11.6 & $18 \pm 2$ \\
\hline
\end{tabular}

${ }^{a}$ See Experimental Section for determination of $K_{\mathrm{D}}$ values. ${ }^{b}$ Determined by factor Xa inhibition method ${ }^{31}$ because the $\Delta F_{\max }$ observed in direct fluorescence titrations was $<5 \% .^{c} \mathrm{DEF}, \mathrm{DEF}-$ $\mathrm{GH}$, and (+)-CS are small sulfated molecules known to activate antithrombin. DEF and DEFGH correspond to specific trisaccharide and pentasaccharide, ${ }^{38}$ while (+)-CS is a synthetic sulfated flavanoid. ${ }^{32} d K_{\mathrm{D}}$ values reported here are taken from ref 20 and not corrected for the small difference in ionic strength at both $\mathrm{pHs}$. ${ }^{e}(+)$-CS and DEFGH $K_{\mathrm{D}}$ values were calculated from the salt dependence of their binding affinity profile. ${ }^{32,38}$

tions of antithrombin with sulfated organic activators and heparin pentasaccharide derivatives. ${ }^{31,32,34}$ Binding of each PAA studied to antithrombin led to a saturable decrease $\left(\Delta F_{\max }=-14\right.$ to $\left.-35 \%\right)$ in TNS fluorescence (Figure 2) from which the equilibrium dissociation constant $\left(K_{\mathrm{D}}\right)$ was determined (Table 1$) .^{35,36}$

The antithrombin binding affinity ranged from $1.0 \mu \mathrm{M}$ for the longest PAA to $2.3 \mu \mathrm{M}$ for the shortest PAA tested at $\mathrm{pH} 6.0$, while the range was $34-180 \mu \mathrm{M}$ at $\mathrm{pH}$ 7.4. This corresponds to a free energy of binding range of $32-35 \mathrm{~kJ} / \mathrm{mol}$ and $21-26 \mathrm{~kJ} / \mathrm{mol}$ at $\mathrm{pH} 6.0$ and 7.4, respectively. Similar values have been observed for trisaccharide $\mathrm{DEF}^{37,38}$ (33 and $24 \mathrm{~kJ} / \mathrm{mol}$ ) and a rationally designed organic activator, catechin sulfate $((+)-$ $\mathrm{CS})^{32}(28$ and $25 \mathrm{~kJ} / \mathrm{mol}$ ) (Table 1), whereas the values are 59 and $51 \mathrm{~kJ} / \mathrm{mol}$ at $\mathrm{pH} 6.0$ and 7.4, respectively, for pentasaccharide DEFGH. ${ }^{37,38}$ Further, the binding energies of PAAs at $\mathrm{pH} 7.4$ are also comparable to lowaffinity heparin $(\sim 25 \mathrm{~kJ} / \mathrm{mol}) .{ }^{21}$

These results suggest that multiple carboxylate groups with appropriate charge density provide sufficient energy to bind antithrombin. It is interesting to note that the binding energies of PAAs are essentially invariant although the chain length increases $\sim 4$-fold, suggesting almost identical binding. The small increase in affinity with the chain length is most likely a statistical phenomenon rather than an engagement of additional interaction sites. This suggests that the affinities being

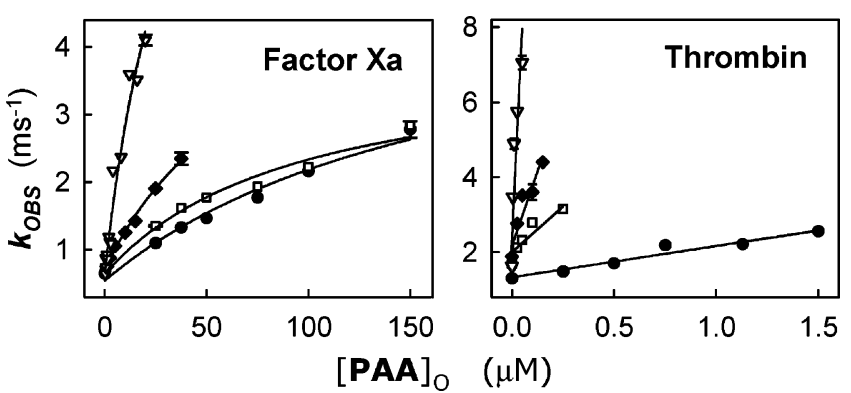

Figure 3. Dependence of the observed pseudo-first-order rate constant $k_{\text {obs }}$ for the inhibition of factor Xa and thrombin at $\mathrm{pH} 7.4$ as a function of PAA concentration. (PAA1500 (๑), PAA2280 ( $\square)$, PAA3450 ( ), and PAA6200 $(\nabla))$ See Experimental Section for details on measurement of $k_{\text {obs }}$.

measured are apparent values and that the intrinsic affinity of antithrombin for a unique PAA site is likely to be different. It is difficult to quantitate this intrinsic site affinity because of conformational flexibility of PAA chains as well as the possibility of overlapping binding sites.

The crystal structure of antithrombin-pentasaccharide complex shows the presence of an extended electropositive domain consisting of the so-called pentasaccharide-binding site and the extended heparin-binding site. ${ }^{5,32,39}$ The combined length of both these sites is $\sim 30$ $\AA$, which is equivalent to the extended length of the smallest PAA studied ( $\sim 40 \AA)$. It is likely that the PAAs engage both these sites, although this remains to be conclusively demonstrated.

Acceleration of Factor Xa Inhibition by PAA. To test whether PAA binding to antithrombin results in accelerated inhibition of procoagulant enzymes, we measured the second-order rate constant of antithrombin inhibition of thrombin and factor $\mathrm{Xa}$ in the presence and absence of PAA at $\mathrm{pH} 6.0$ and $\mathrm{pH} 7.4$ (Figure 3). ${ }^{35}$ Table 2 lists the second-order rate constants and the acceleration in inhibition achieved for the four PAAs studied.

The second-order rate constant for antithrombin inhibition of factor $\mathrm{Xa}$ at $\mathrm{pH} 6.0$ increased from 3200 $\mathrm{M}^{-1} \mathrm{~s}^{-1}$ for PAA1500 to $59300 \mathrm{M}^{-1} \mathrm{~s}^{-1}$ for PAA6200. Thus, the acceleration $\left(k_{\text {cat }} / k_{\text {uncat }}\right)$ in factor Xa inhibition increased from about 15-fold to 284-fold as the length of the chain increased. Further, smaller chains PAA1070 and PAA 830 retained the 15 -fold acceleration shown by PAA1500 (not shown). Thus, acceleration shows chain length dependence beyond $\sim 21$ monomers. These accelerations compare favorably with heparin saccharides DEF and DEFGH $(\sim 300 \text {-fold })^{37,38}$ and are significantly better than the rationally designed molecule (+)-CS (21fold) ${ }^{32,33}$ In contrast, at $\mathrm{pH} 7.4$ the $k_{\text {cat }}$ for PAAs ranged from $11400 \mathrm{M}^{-1} \mathrm{~s}^{-1}$ to $23100 \mathrm{M}^{-1} \mathrm{~s}^{-1}$, suggesting considerably weak acceleration. Under similar conditions, heparin saccharides show $\sim 300$-fold acceleration. 37,38

Although the mechanism of heparin (and pentasaccharide DEFGH) acceleration of antithrombin inhibition of factor Xa involves the conformational activation of the inhibitor, ${ }^{5,40,41}$ recent work suggests a significant bridging component, especially with longer heparin chains, wherein the activator bridges the inhibitor and the enzyme in a ternary complex in the presence of $\mathrm{Ca}^{2+}$ ions. ${ }^{42,43}$ The increase in acceleration with PAA chain 
Table 2. Second-Order Rate Constants $\left(k_{\text {cat }}\right)$ for Antithrombin-PAA Inhibition of Factor Xa and Thrombin at $\mathrm{pH} 6.0$ and 7.4

\begin{tabular}{|c|c|c|c|c|c|c|c|c|}
\hline & \multicolumn{4}{|c|}{ factor $\mathrm{Xa}$} & \multicolumn{4}{|c|}{ thrombin } \\
\hline & \multicolumn{2}{|c|}{$\mathrm{pH} 6.0, I 0.05,25^{\circ} \mathrm{C}$} & \multicolumn{2}{|c|}{$\mathrm{pH} 7.4, I 0.075,25^{\circ} \mathrm{C}$} & \multicolumn{2}{|c|}{$\mathrm{pH} 6.0, I 0.05,25^{\circ} \mathrm{C}$} & \multicolumn{2}{|c|}{$\mathrm{pH} 7.4, I 0.075,25^{\circ} \mathrm{C}$} \\
\hline & $k_{\mathrm{CAT}}\left(\mathrm{mM}^{-1} \mathrm{~s}^{-1}\right)$ & $k_{\mathrm{CAT}} / k_{\mathrm{UNCAT}}$ & $k_{\mathrm{CAT}}\left(\mathrm{mM}^{-1} \mathrm{~s}^{-1}\right)$ & $k_{\mathrm{CAT}} / k_{\mathrm{UNCAT}}$ & $k_{\mathrm{CAT}}\left(\mathrm{mM}^{-1} \mathrm{~s}^{-1}\right)$ & $k_{\mathrm{CAT}} / k_{\mathrm{UNCAT}}$ & $k_{\mathrm{CAT}}\left(\mathrm{mM}^{-1} \mathrm{~s}^{-1}\right)$ & $k_{\mathrm{CAT}} / k_{\mathrm{UNCAT}}$ \\
\hline PAA1500 & $3.2 \pm 0.4$ & $15^{a}$ & $11.4 \pm 0.5$ & $9.5^{a}$ & $13 \pm 1$ & $24^{a}$ & $1030 \pm 120$ & $114^{a}$ \\
\hline PAA2280 & $13.1 \pm 0.8$ & 63 & $8.8 \pm 0.4$ & 6.2 & $71 \pm 2$ & 125 & $3390 \pm 810$ & 259 \\
\hline PAA3450 & $32.0 \pm 2.2$ & 153 & $13.9 \pm 0.3$ & 8.7 & $196 \pm 3$ & 345 & $9000 \pm 1900$ & 597 \\
\hline PAA6200 & $59.3 \pm 3.3$ & 284 & $23.1 \pm 1.2$ & 17 & $793 \pm 80$ & 1392 & $19100 \pm 5300$ & 1109 \\
\hline
\end{tabular}

${ }^{a}$ The uncatalyzed second-order rate constant $k_{\text {uncat }}$ under each condition was determined from the intercept of the pseudo-first-order rate constant $k_{\mathrm{obs}}-[\mathrm{PAA}]_{\mathrm{O}}$ profile at $\mathrm{pH} 7.4$. At $\mathrm{pH} 6.0$, independently measured $k_{\text {uncat }}$ was used because of the small value of the intercept, which tended to give inaccurate $k_{\text {uncat. }}$ The $k_{\text {uncat }}$ values were found to be $2100 \pm 50 \mathrm{M}^{-1} \mathrm{~s}^{-1}$ and $210 \pm 10 \mathrm{M}^{-1} \mathrm{~s}^{-1}$ for factor Xa at pH 7.4 and $\mathrm{pH} 6.0$, respectively, while the values were $13840 \pm 125 \mathrm{M}^{-1} \mathrm{~s}^{-1}$ and $570 \pm 27 \mathrm{M}^{-1} \mathrm{~s}^{-1}$ for thrombin.

length at $\mathrm{pH} 6.0$ suggest such a bridging mechanism, while this effect is abolished at $\mathrm{pH}$ 7.4.

A plausible explanation for this differential behavior can be obtained from heparin acceleration studies. Studies with factor $\mathrm{Xa}$ derivatives suggest that the anionic Gla domain, when not neutralized by $\mathrm{Ca}^{2+}$ ions, interferes with heparin binding, preventing bridging and acceleration. ${ }^{44}$ Thus, at $\mathrm{pH} 7.4$ in the absence of $\mathrm{Ca}^{2+}$ ions, acceleration due to bridging is not expected for PAA molecules, while partial or complete neutralization of the Gla residues at $\mathrm{pH} 6.0$ likely induces ternary complex formation resulting in significant acceleration. Finally, it is interesting to note that the acceleration achieved ( $\sim 20$-fold) at $\mathrm{pH} 7.4$ is similar to that achieved with (+)-CS, a small sulfated molecule that cannot form the ternary complex. ${ }^{32,33}$

Acceleration of Thrombin Inhibition by PAA. The second-order rate constant for PAA-catalyzed thrombin inhibition increased from $13400 \mathrm{M}^{-1} \mathrm{~s}^{-1}$ to 793000 $\mathrm{M}^{-1} \mathrm{~s}^{-1}$ at $\mathrm{pH} 6.0$ and from $1030000 \mathrm{M}^{-1} \mathrm{~s}^{-1}$ to $19100000 \mathrm{M}^{-1} \mathrm{~s}^{-1}$ at $\mathrm{pH} 7.4$ as the chain length increased (Table 2). These correspond to a dramatic increase in acceleration of thrombin inhibition from 24fold to 1392-fold at $\mathrm{pH} 6.0$ and from 114-fold to 1109fold at $\mathrm{pH}$ 7.4. For full-length heparin, the second-order rate constant for thrombin inhibition was measured to be $37000000 \mathrm{M}^{-1} \mathrm{~s}^{-1}$ corresponding to an acceleration of $\sim 4000$-fold. ${ }^{40,41}$ In contrast, low-affinity heparin accelerates antithrombin-dependent thrombin inhibition 60 -fold. ${ }^{21}$

The results demonstrate that PAAs are significantly better than low-affinity heparin in accelerating thrombin inhibition. Yet, it is important to recognize that the second-order rate constants derived in this study are obtained at low antithrombin saturations and therefore represent values obtained after significant extrapolations. Detailed mechanistic studies on the order of formation and affinities involved in antithrombinPAA - thrombin ternary complex are needed to ascertain the accelerations reported here. However, the results demonstrate that PAAs accelerate thrombin inhibition by antithrombin in a chain length-dependent manner at both $\mathrm{pHs}$.

\section{Discussion}

Several points about PAA are attractive. Assuming full chain extension and ionization of all carboxylic acid moieties, PAAs carry a charge density of $\sim-0.46$ charges per $\AA$, which is similar to the average charge density of $-0.4-0.5$ for heparin. (The average disaccharide in heparin contains 2.5 sulfate groups and a carboxylate, while typical end-to-end distance between $\mathrm{C}-1$ of reduc- ing-end residue and $\mathrm{C}-4$ of nonreducing end residue is in the range of 7-8 $\AA$. Thus the average charge density for heparin turns out to be approximately -0.44-0.5 charges per $\AA$.) The primarily alkyl backbone is flexible; thus, the probability of inducing interaction with antithrombin is high. Finally, modeling shows that the carboxylate groups of PAA can organize to form a linear negatively charged "face", which may engage the heparin-binding site of the inhibitor. ${ }^{39}$

Overall, the results suggest that carboxylate-based polymers, poly(acrylic acid)s, bind and activate antithrombin for accelerated inhibition of factor $\mathrm{Xa}$ and thrombin. This principle is critical to establish because it has been widely believed, but not rigorously demonstrated, that replacing sulfates in the antithrombinbinding domain with any other anions nullifies the anticoagulant activity. This understanding arose following the observation that replacing a specific sulfate group of the sequence-specific pentasaccharide DEFGH with a phosphate group dramatically reduces antithrombin binding. ${ }^{45}$ The reduced binding affinity could have arisen from the loss of a critical sulfate, or from the introduction of phosphate, or from a subtle conformational change in the activator.

The understanding that sulfated polymers are necessary was also furthered by the observation that whereas polyaspartic acid, a carboxylic acid polymer, was an effective accelerator of heparin cofactor II-proteinase reactions, it failed to enhance antithrombin reactions with thrombin. ${ }^{46}$ Modeling reveals that polyaspartate polymer has a charge density of -0.31 charges per $\AA$, approximately $33 \%$ lower than PAA. Thus, our results with PAAs are extremely interesting because they demonstrate some structural requirements, specifically the need for appropriate charge density.

Despite this interesting property, one must exercise caution in overinterpreting the results described here. We do not expect PAA to function as anticoagulants in vivo, although an activated partial thromboplastin test of at least one PAA indicated a dose-dependent lengthening of clotting time (not shown). This is because the binding affinities at $\mathrm{pH} 7.4$ are fairly weak (Table 1). In addition, the potentially high charge density of these polymers would suggest that they interact with available cationic proteins, including platelet factor 4 . However, the work highlights the need to investigate PAAantithrombin-thrombin interaction for elucidating design principles.

On the basis of this work, one can predict that antithrombin activators based primarily on carboxylic acid groups may be rationally designed in three steps. These steps include designing carboxylate-based organic 
scaffolds that interact with heparin-binding sites in antithrombin and in thrombin, followed by designing a neutral linker that could connect these two domains. Such carboxylic acid-based two-domain organic molecules may provide us with orally bioavailable antithrombin activators.

\section{Conclusions}

Our work demonstrates a proof-of-principle that organic, nonsulfated, nonsaccharidic molecules, containing only carboxylic acid groups, can bind and activate antithrombin for accelerated inhibition of two critical enzymes, thrombin and factor $\mathrm{Xa}$, of the coagulation cascade.

\section{Experimental Section}

Proteins and Chemicals. Human antithrombin and $\alpha$-thrombin were generous gifts from Professor Steven Olson of the University of Illinois (Chicago). Human factor Xa was purchased from Hematologic Technology (Essex Junction, VT) and 2-( $p$-toluidino)naphthalene-6-sulfonic acid (TNS) from Sigma-Aldrich (Milwaukee, WI). Poly(acrylic acid)s PAA2280, PAA3450, and PAA6200 were acquired from American Polymer Standards (Mentor, OH); PAA1500 was from Polymer Source (Dorval, Quebec).

Fluorescence Spectroscopy and Equilibrium Binding Studies. Fluorescence experiments were performed with a PCI Spectrofluorometer (ISS Instruments, Champaign, IL) at room temperature. Equilibrium dissociation constants $\left(K_{\mathrm{D}}\right)$ for the interaction of PAA with plasma antithrombin were determined by titrating the polymer into a solution of antithrombin-TNS complex and monitoring the decrease in the fluorescence at $432 \mathrm{~nm}\left(\lambda_{\mathrm{ex}}=330 \mathrm{~nm}\right)$. Titrations of $0.95-1.9 \mu \mathrm{M}$ antithrombin and $5.5 \mu \mathrm{M}$ TNS were carried out in $20 \mathrm{mM}$ sodium phosphate buffer containing $20 \mathrm{mM} \mathrm{NaCl}, 0.1 \mathrm{mM}$ EDTA, and $0.1 \%$ PEG8000, adjusted to $\mathrm{pH} 6.0$ or 7.4. Two or three averaged measurements were fit to the quadratic equilibrium binding equation to determine the $K_{\mathrm{D}}$ of interaction, ${ }^{30,31}$ assuming a 1:1 binding model for the interaction of antithrombin with PAA1500, PAA2280, and PAA3450, and a 2:1 model for PAA6200. Activity of antithrombin was checked before and after titrations to ensure absence of aggregation.

Inhibition of Factor Xa and Thrombin. The rate of PAAcatalyzed antithrombin inhibition of factor Xa or thrombin was determined by monitoring the pseudo first-order rate constant $\left(k_{\text {obs }}\right)$ as a function of concentration of PAA with $150-450 \mathrm{nM}$ antithrombin and $20-30 \mathrm{nM}$ factor Xa or $150 \mathrm{nM}$ antithrombin and $15 \mathrm{nM}$ thrombin. ${ }^{34,39}$ The reactions were carried out in PEG20K-coated cuvettes at $25^{\circ} \mathrm{C}$ in $20 \mathrm{mM}$ sodium phosphate containing $20 \mathrm{mM} \mathrm{NaCl}, 0.1 \mathrm{mM}$ EDTA, and 0.1\% PEG8000 at either $\mathrm{pH} 6.0$ or $\mathrm{pH}$ 7.4. The $k_{\text {obs }}$ at each $[\mathrm{PAA}]_{O}$ was determined by monitoring the residual enzyme activity as a function of time using either Spectrozyme fXa (factor Xa) or S2238 (thrombin) as chromogenic substrates. ${ }^{30,31,37}$ The $[\mathrm{PAA}]_{\mathrm{O}}$ chosen resulted in antithrombin saturation of $0.5-15 \%$ for thrombin and 25-50\% for factor Xa. The second-order rate constant $k_{\text {cat }}$ of the enzyme inhibition was then determined by fitting $k_{\text {obs }}$ dependence on $[\mathrm{PAA}]_{O}$ with equation $k_{\text {obs }}=k_{\text {uncat }}$ $[\mathrm{AT}]+k_{\text {cat }}[\mathrm{AT}: \mathrm{PAA}]$, where the second-order uncatalyzed rate constant $k_{\text {uncat }}$ was determined independently and [AT:PAA] was obtained using the quadratic equilibrium binding equation. ${ }^{34,37}$

Acknowledgment. We thank Professor Steven T. Olson (University of Illinois-Chicago) for his critical comments and his generous gift of human factor $\mathrm{Xa}$ and thrombin. This work was supportedby grants from the National Heart, Lung and Blood Institute (RO1 HL 069975), the American Heart Association (0256286U and 9960250U), and the A. D. Williams Foundation.

\section{References}

(1) Gettins, P. G. W. Serpin structure, mechanism and function. Chem. Rev. 2002, 102, 4751-4803.

(2) Gettins, P. G. W.; Patston, P. A.; Olson, S. T. Serpins: Structure, Function and Biology; R G Landes Company: New York, 1966

(3) Rosenberg, R. D.; Damus, P. S. The purification and mechanism of action of human antithrombin - heparin cofactor. J. Biol. Chem. 1973, 248, 6490-6505.

(4) Damus, P. S.; Hicks, M.; Rosenberg, R. D. Anticoagulant action of heparin. Nature 1973, 246, 355-357.

(5) Desai, U. R. New antithrombin-based anticoagulants. Med. Res. Rev. 2004, 24, 151-181.

(6) Petitou, M.; van Boeckel, C. A. A synthetic antithrombin III binding pentasaccharide is now a drug! What comes next? Angew. Chem., Int. Ed. 2004, 43, 3118-3133.

(7) Gunay, N. S.; Linhardt, R. J. Heparinoids: structure, biological activities and therapeutic applications. Planta Med. 1999, 65, 301-306.

(8) van Boeckel, C. A. A.; Petitou M. The unique antithrombin III binding domain of heparin: A lead to new synthetic antithrombotics. Angew. Chem., Int. Ed. 1993, 32, 1671-1690.

(9) Petitou, M.; Casu, B.; Lindahl, U. 1976-1983, a critical period in the history of heparin: the discovery of the antithrombin binding site. Biochimie 2003, 85, 83-89.

(10) Karst, N. A.; Linhardt, R. J. Recent chemical and enzymatic approaches to the synthesis of glycosaminoglycan oligosaccharides. Curr. Med. Chem. 2003, 10, 1993-2031.

(11) Sundaram, M.; Qi, Y.; Shriver, Z.; Liu, D.; Zhao, G.; Venkataraman, G.; Langer, R.; Sasisekharan, R. Rational design of lowmolecular weight heparins with improved in vivo activity. Proc. Natl. Acad. Sci. U.S.A. 2003, 100, 651-656.

(12) Kuberan, B.; Lech, M. Z.; Beeler, D. L.; Wu, Z. L.; Rosenberg, R. D. Enzymatic synthesis of antithrombin III-binding heparan sulfate pentasaccharide. Nat. Biotechnol. 2003, 21, 1343-1346.

(13) Kuberan, B.; Beeler, D. L.; Lawrence, R.; Lech, M.; Rosenberg, R. D. Rapid two-step synthesis of mitrin from heparosan: a replacement for heparin. J. Am. Chem. Soc. 2003, 125, 1242412425 .

(14) Kuberan, B.; Beeler, D. L.; Lech, M.; Wu, Z. L.; Rosenberg, R. D. Chemoenzymatic synthesis of classical and nonclassical anticoagulant heparan sulfate polysaccharides. J. Biol. Chem. 2003, 278, 52613-52621.

(15) Buijsman, R. C.; Basten, J. E. M.; Dreef-Tromp, C. M.; van der Marel, G. A.; van Boeckel, C. A. A.; van Boom, J. H. Synthesis of heparin-like antithrombotics having perphosphorylated thrombin binding domains. Bioorg. Med. Chem. 1999, 7, 1881-1890.

(16) Buijsman R. C.; Basten, J. E.; van Dinther, T. G.; van der Marel G. A.; van Boeckel, C. A.; van Boom, J. H. Design and synthesis of a novel synthetic NAPAP-pentasaccharide conjugate displaying a dual antithrombotic action. Bioorg. Med. Chem. Lett. 1999 9, 2013-2018.

(17) Buijsman, R. C.; Kuijpers, W. H. A.; Basten, J. E. M.; KuylYeheskiely, E.; van der Marel, G. A.; van Boeckel, C. A. A Synthesis of a pentasaccharide-oligodeoxyribonucleotide conjugate: a novel antithrombotic agent.. Chem. Eur. J. 1996, 2, 1572-1577.

(18) Lindahl, U.; Backstrom, G.; Thunberg, L.; Leder, I. G. Evidence for a 3-O-sulfated D-glucosamine residue in the antithrombinbinding sequence of heparin. Proc. Natl. Acad. Sci., U.S.A. 1980 , $77,6551-6555$

(19) Atha, D. H.; Stephens, A. W.; Rimon, A.; Rosenberg, R. D. Sequence variation in heparin octasaccharides with high affinity from antithrombin III. Biochemistry 1984, 23, 5801-5812.

(20) Lindahl, U.; Thunberg, L.; Backström, G.; Riesenfeld, J.; Nordling, K.; Björk, I. Extension and structural variability of the antithrombin-binding sequence in heparin. J. Biol. Chem. 1984, $259,12368-12376$

(21) Streusand, V. J.; Björk, I.; Gettins, P. G. W.; Petitou, M.; Olson, S. T. Mechanism of acceleration of antithrombin-proteinase reactions by low affinity heparin: Role of the antithrombin binding pentasaccharide in heparin rate enhancement. J. Biol. Chem. 1995, 270, 9043-9051.

(22) Cardin, A. D.; Weintraub, H. J. R. Molecular modeling of proteinglycosaminoglycan interactions. Arteriosclerosis 1989, 9, 21-32.

(23) Hileman, R. E.; Fromm, J. R.; Weiler, J. M.; Linhardt, R. J. Glycosaminoglycan-protein interactions: definition of consensus sites in glycosaminoglycan binding proteins. BioEssays 1998, 20, 156-167.

(24) Capila, I.; Linhardt, R. L. Heparin-protein interactions. Angew. Chem., Int. Ed. 2002, 41, 390-412.

(25) Ginsberg, J. A.; Crowther, M. A.; White, R. H.; Ortel, T. L. Anticoagulation therapy. Hematology 2001, 339-357.

(26) Agnelli, G.; Sonaglia, F. Perspectives on antithrombotic agents: from unfractionated heparin to new antithrombotics. Haematologica 2002, 87, 757-70. 
(27) Eriksson, B. I.; Bauer, K. A.; Lassen, M. R.; Turpie, A. G. G. Fondaparinux compared with enoxaparin for the prevention of venous thromboembolism after hip-fracture surgery. New Engl. J. Med. 2001, 345, 1298-1304.

(28) Turpie, A. G.; Bauer, K. A.; Eriksson, B. I.; Lassen, M. R. Fondaparinux vs enoxaparin for the prevention of venous thromboembolism in major orthopedic surgery: a meta-analysis of 4 randomized double-blind studies. Arch. Intern. Med. 2002, $162,1833-1840$.

(29) Samama, M. M.; Gerotziafas, G. T. In vitro effect of melagatran and lepirudin on clot-bound thrombin. Thromb. Res. 2003, 109, $1-11$

(30) Turpie, A.; Bauer, K.; Eriksson, B.; Lassen, M. Efficacy and safety of fondaparinux in major orthopedic surgery according to the timing of its first administration. Thromb. Haemost. 2003, 90, 364-366.

(31) Gunnarsson, G. T.; Desai, U. R. Exploring new nonsugar sulfated molecules as activators of antithrombin. Bioorg. Med. Chem. Lett. 2003, 13, 579-583.

(32) Gunnarsson, G. T; Desai, U. R. Interaction of sulfated flavanoids with antithrombin: Lessons on the design of organic activators. J. Med. Chem. 2002, 45, 4460-4470.

(33) Gunnarsson, G. T.; Desai, U. R. Designing small, nonsugar activators of antithrombin using hydropathic interaction analyses. J. Med. Chem. 2002, 45, 1233-1243.

(34) Meagher, J. L.; Olson, S. T.; Gettins, P. G. W. Critical role of the linker region between helix $\mathrm{D}$ and strand $2 \mathrm{~A}$ in heparin activation of antithrombin. J. Biol. Chem. 2000, 275, 2698-2704.

(35) Olson, S. T.; Björk, I.; Shore, J. D. Kinetic characterization of heparin-catalyzed and uncatalyzed inhibition of blood coagulation proteinases by antithrombin. Methods Enzymol. 1993, 222, $525-560$.

(36) Eftink, M. R. Fluorescence methods for studying equilibrium macromolecule-ligand interactions. Methods Enzymol. 1997, 278, $221-257$.

(37) Desai, U. R.; Petitou, M.; Björk, I.; Olson, S. T. Mechanism of heparin activation of antithrombin: Evidence for an inducedfit model of allosteric activation involving two interaction subsites. Biochemistry 1998, 37, 7, 13033-13041.
(38) Desai, U. R.; Petitou, M.; Björk, I.; Olson, S. T. Mechanism of heparin activation of antithrombin: Role of individual residues of the pentasaccharide activating sequence in the recognition of native and activated states of antithrombin. J. Biol. Chem. 1998, 273, 7478-7487.

(39) Jin, L.; Abrahams, J.-P.; Skinner, R.; Petitou, M.; Pike, R. N.; Carrell, R. W. The anticoagulant activation of antithrombin by heparin. Proc. Natl. Acad. Sci., U.S.A. 1997, 94, 14683-14688

(40) Olson, S. T.; Björk, I. Predominant contribution of surface approximation to the mechanism of heparin acceleration of the antithrombin-thrombin reaction. Elucidation from salt concentration effects. J. Biol. Chem. 1991, 266, 6353-6364.

(41) Olson, S. T; Björk, I; Sheffer, R.; Craig, P. A; Shore, J. D Choay, J. Role of the antithrombin-binding pentasaccharide in heparin acceleration of antithrombin-proteinase reactions. Resolution of the antithrombin conformational change contribution to heparin rate enhancement. J. Biol. Chem. 1992, 267, 1252812538.

(42) Rezaie, A. R. Identification of basic residues in the heparinbinding exosite of factor $\mathrm{Xa}$ critical for heparin and factor $\mathrm{Va}$ binding. J. Biol. Chem. 2000, 275, 3320-3327.

(43) Rezaie, A. R.; Olson, S. T. Calcium enhances heparin catalysis of the antithrombin-factor $\mathrm{Xa}$ reaction by promoting the assembly of an intermediate heparin-antithrombin-factor Xa bridging complex. Demonstration by rapid kinetics studies. Biochemistry 2000, 39, 12083-12090.

(44) Rezaie, A. R. Heparin binding exosite of factor Xa. Trends Cardiovasc. Med. 2000, 10, 333-338.

(45) Vos, J. N.; Westerdiun, P.; van Boeckel, C. A. A. Synthesis of 6-O-phosphorylated analogue of the antithrombin III binding sequence of heparin: replacement of one essential sulphate group by a phosphate group nullifies the biological activity. Bioorg. Med. Chem. Lett. 1991, 1, 143-146.

(46) Church, F. C.; Treanor, R. E.; Sherrill, G. B.; Whinna, H. C Carboxylate polyanions accelerate inhibition of thrombin by heparin cofactor II. Biochem. Biophys. Res. Commun. 1987, 148, $362-368$.

JM0492960 